\title{
Degradation of endophyte alkaloids in field-dried cut ryegrass herbage
}

\author{
D.E. HUME, M.J. HICKEY and B.A. TAPPER \\ AgResearch, Grasslands Research Centre, PB 11008, Palmerston North 4442, New Zealand \\ david.hume@agresearch.co.nz
}

\begin{abstract}
The stability of endophyte alkaloids was investigated in ryegrass herbage cut and then dried in the field under a simulated hay drying regime in early and mid-summer. Ryegrass (Lolium perenne) infected with typical 'wild-type' and the 'AR37' strain of endophyte (Neotyphodium lolii) was measured for peramine, ergovaline and lolitrem B for wild-type, and epoxy-janthitrems for AR37. Despite very contrasting weather conditions, relative decline in alkaloid concentrations was similar in both early and mid-summer. Concentrations had halved within 5 to 7 days, except for lolitrem B in mid-summer which had no decline until after 4 days of drying. Ergovaline showed quite variable and erratic responses over time possibly due to the low concentrations in the cut herbage. At least in the mid-summer experiment, if herbage had been conserved at the time of normal haying making, alkaloid concentrations would have been similar to those of the herbage at the time of cutting.
\end{abstract}

Keywords: endophyte, Neotyphodium lolii, Lolium perenne, peramine, lolitrem, ergovaline, janthitrems

\section{Introduction}

Perennial ryegrasses (Lolium perenne) are commonly infected with Neotyphodium lolii endophyte, with the resulting symbiotic association producing a number of alkaloids. Typically New Zealand ryegrass pastures, and in the past, most ryegrass cultivars, have been naturally infected with a "wild-type" strain or strains. These produce three classes of alkaloids that are routinely quantified as they play key roles in the bioactivity of these associations. Peramine is a pyrrolopyrazine with significant insect feeding deterrence but lacking mammalian toxicity. Lolitrem B, an indole diterpene with a specific pattern of isoprenyl derived decoration, is generally the most abundant and potent tremorgen being the likely prime cause of ryegrass staggers in grazing livestock. Lysergyl alkaloids, primarily measured as ergovaline, are also produced and contribute to heat stress and reduced liveweight gains. The lolitrems and lysergyls also play a role in insect pest protection.

A new endophyte strain, AR37, currently being commercialised in New Zealand ryegrasses, has none of these alkaloids. It does produce indole diterpene alkaloids of the janthitrem group, notably 11,12-epoxy-janthitrem G and related epoxy-janthitrems (Tapper \& Lane 2004). These differ from lolitrems in the decoration of the indole moiety. These epoxy-janthitrems may account for some enhanced pest protection and performance of ryegrass plants infected with AR37 (Fletcher 2005; Hume et al. 2005; Popay \& Bonos 2005). They may also be a risk for causing a mild form of ryegrass staggers occasionally observed in sheep (Fletcher 2005).

The stability of these mammalian toxins is of interest when conserved as silage or hay. Fink-Gremmels (2005) and Fletcher (2005) report stability of lolitrem B, but not ergovaline. No reports are available on epoxy-janthitrems. This project investigated the alkaloid concentrations of endophyte-infected ryegrass cut and dried under conditions similar to hay drying in the field.

\section{Materials and Methods}

\section{Experiment 1}

In early spring (September 2004), propagating trays filled with a peat/sand mix were each sown with 96 seeds of two perennial ryegrasses; cultivar Grasslands Samson infected with its endemic "wild-type" endophyte ( $88 \%$ viable endophyte) and a closely related selection GA142 infected with the AR37 endophyte

Figure 1 Dry matter content (\%) of ryegrass tillers cut in early (dotted line) and mid-summer (solid line) as they dried under field conditions. Mean of AR37 and Wild-type. Bars indicate SEM.

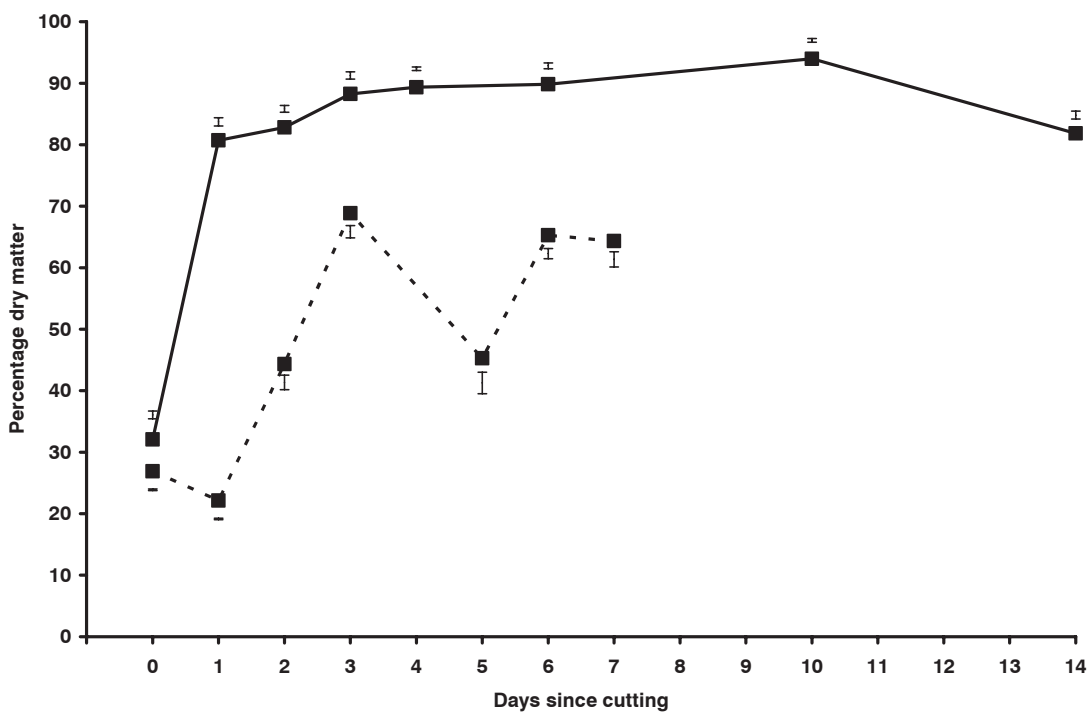


strain $(76 \%$ viable endophyte). Trays were placed in a heated glasshouse with 18 to $24^{\circ} \mathrm{C}$ daytime maximum temperatures and an automatic capillary mat watering system. Plants were trimmed to $4 \mathrm{~cm}$ height after 5 and 9 weeks of growth. Thirteen weeks after sowing (1 December 2004) the regrowth was sampled to a height of $1 \mathrm{~cm}$ at 1:30 pm from two replicate trays of AR37 and one of the wild-type treatments. The cut herbage included some dead material on the tiller bases but no reproductive tillers. A subsample of approximately 75-85 tillers was taken at random and this herbage was weighed and immediately placed in a freezer. The remaining herbage was placed in a thin layer $(2-3 \mathrm{~cm}$ thick) on green propagating seed trays and placed outside on closely mown grass. This herbage was subsampled on six occasions over the next 7 days at approximately 1:30 pm each day, using the same procedures as described above for herbage cut on Day 0 .

\section{Experiment 2}

This experiment used the trays grown in Experiment 1 and a further set of trays of Samson AR37 (83\% infected) and Samson wild-type ( $98 \%$ infected) resulting in four replicates of AR37 and three of wild-type. All lines were grown in a glasshouse over early/mid-summer under temperature and water conditions similar to those of Experiment 1. In mid-summer (15 January 2005), herbage was cut to $1 \mathrm{~cm}$ height, and as described above, dried in the field, sub-sampled for up to 14 days, and analysed for endophyte alkaloids and moisture content.

\section{Analysis}

All herbage samples were freeze-dried, weighed to determine dry matter (DM) content and milled to pass through a $1 \mathrm{~mm}$ sieve. Herbage infected with wild-type endophyte was analysed by HPLC for ergovaline and peramine based on the technique of Spiering et al. (2002) and lolitrem B using the procedures of Gallagher et al. (1985). Ergovaline concentrations reported are the sum of measured ergovaline and ergovalinine. Herbage infected with AR37 endophyte was analysed for 11,12-epoxy-janthitrems using HPLC as reported by Tapper \& Lane (2004). Four epoxy-janthitrems were measured. At the time, no janthitrem standard was available so the concentrations are relative and in arbitrary units.

\section{Results and Discussion}

\section{Herbage drying}

Herbage cut in early summer dried at a slower rate and did not dry out as much as the herbage cut in mid-summer (Fig. 1). This corresponded with considerably warmer and drier weather in midsummer than early summer. Mean air temperatures were 17.9 and $13.8^{\circ} \mathrm{C}$ (10 minute readings), mean daily solar radiation 25 and $19 \mathrm{MJ}$, mean daily sunshine 8.5 and 4.6 hours, with rainfall of 0.4 and $35.2 \mathrm{~mm}$ (over 3 days, with $31.6 \mathrm{~mm}$ on Day 4) for the midsummer and early summer experiments, respectively.

In terms of hay making, a safe DM content to bale hay ranges from 75 to $85 \%$ (Smetham 1990). The ryegrass cut and dried in early summer only ever reached a maximum DM content of $69 \%$, while within 24 hours the ryegrass cut in mid-summer was at $80 \%$ DM content. While these represent the extremes in conditions and lengths of time to dry hay, the samples analysed would only reflect what would be occurring at the top few layers of a hay swathe, and not representative of the total depth of a swathe which could be 20 to $30 \mathrm{~cm}$ deep.

\section{Alkaloid concentrations}

Endophyte alkaloid concentrations at the time of cutting (Table 1) were 22 to $40 \%$ lower in mid-summer than in early summer, except for ergovaline which was $73 \%$ higher in mid-summer but still relatively low. Only the sum of the epoxy-janthitrems are presented as the four epoxy-janthitrems were highly correlated $(\mathrm{r}=0.97)$.

The change in concentration of each alkaloid over time was expressed relative to the concentrations at the time of cutting (Figs. 2a-c). Peramine, lolitrem B and total janthitrems generally exhibited a similar pattern of linear or curva-linear decline. Generally the decline in these alkaloids was not immediate, particularly for lolitrem B in mid-summer which remained high up to 4 days after cutting. For peramine and total janthitrems, a $50 \%$ decline occurred within 5 to 7 days in both experiments, despite the contrasting weather conditions in early and midsummer. In contrast, ergovaline was not detectable from Days 5 and 10 onwards in the early and mid-summer experiments, respectively, and showed quite variable and erratic responses over time.

Compared with DM content, all alkaloids showed considerable variation between reps (i.e. high SEM). This was highest for ergovaline, which may have been due to the low concentrations resulting in many values being at or below the limits of detection of 0.05 to $0.10 \mathrm{ppm}$. Total janthitrems showed less variation than lolitrem B but this was based on more replication for the janthitrems. Peramine showed the least variation.

Fletcher (2005) monitored ergovaline and lolitrem B in silage and hay conserved after up to 8 days of drying under normal procedures on farm. Decline in ergovaline concentrations was greater, the longer herbage was field dried and the longer it was stored. In contrast, lolitrem B had similar concentrations to that of the cut herbage even after 6 and 8 days of field drying. Fletcher's (2005) observations support our results for the relative stability of these alkaloids.

It is interesting that despite these alkaloids being from diverse chemical groups they displayed relatively similar stability, and under quite contrasting weather conditions. All these alkaloids are sensitive to degradation by light/UV, but most particularly ergovaline. In comparison, dead endophyte-infected ryegrass material mostly at the base of pastures, typically has very low or no peramine and ergovaline, but high levels of lolitrem B and janthitrems (Hume et al. unpublished data). While the processes of tissue senescence and exposure to UV are somewhat different to that of hay drying, there is a clear distinction between these types of material.

In terms of any toxicity of conserved forage, these results support previous work showing that ryegrass hay contains lolitrem

Table 1 Endophyte alkaloid concentrations (ppm) for ryegrass herbage cut directly from trays grown in a glasshouse, before being placed in the field to dry in experiments carried out in early and mid-summer. Epoxyjanthitrems values are relative and in arbitrary units.

\begin{tabular}{llcc}
\hline $\begin{array}{l}\text { Endophyte } \\
\text { strain }\end{array}$ & Endophyte alkaloid & $\begin{array}{c}\text { Early } \\
\text { summer }\end{array}$ & $\begin{array}{c}\text { Mid- } \\
\text { summer }\end{array}$ \\
\hline Wild-type & lolitrem B & 5.1 & 3.0 \\
Wild-type & ergovaline & 0.15 & 0.26 \\
Wild-type & peramine & 29.8 & 23.3 \\
AR37 & epoxy-janthitrem A1 & 0.56 & 0.40 \\
AR37 & epoxy-janthitrem A2 & 0.57 & 0.39 \\
AR37 & epoxy-janthitrem A3 & 1.15 & 0.76 \\
AR37 & epoxy-janthitrem B & 2.00 & 1.25 \\
AR37 & total epoxy-janthitrems & 4.27 & 2.80 \\
\hline
\end{tabular}


Figure 2 Relative decline in endophyte alkaloids in ryegrass tillers cut in early (dotted line) and mid-summer (solid line) as tillers dried under field conditions. (A) Peramine. (B) Ergovaline. (C) Lolitrem B and total epoxy-janthitrems. Values are relative to alkaloid concentrations at the time of cutting (Day 0$)(=100)$. Bars indicate SEM for treatments with replication.
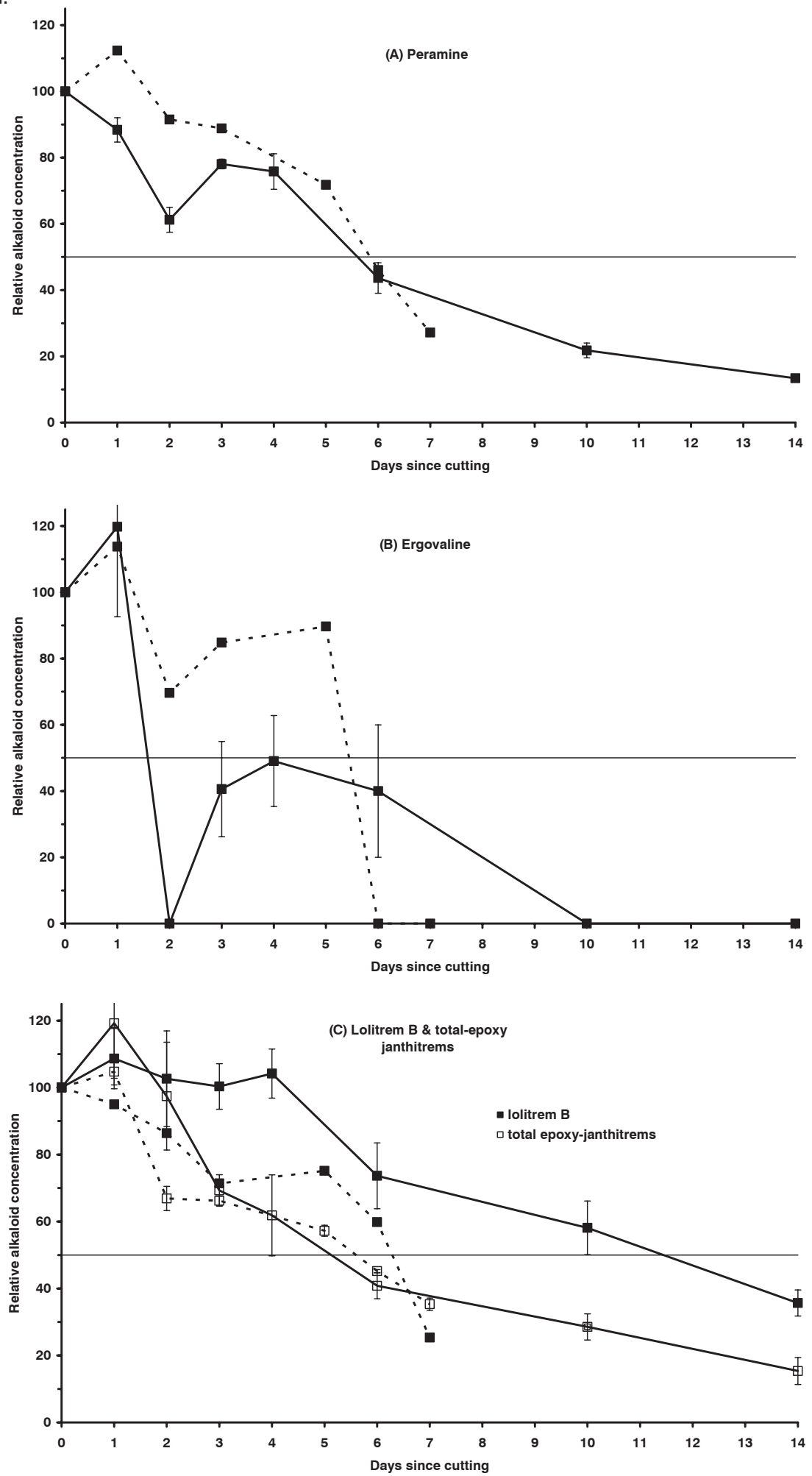
B when infected with wild-type endophyte (Fink-Gremmels 2005; Fletcher 2005). Similarly, our results show that hay may contain epoxy-janthitrems when infected with endophyte AR37, although the longer term stability of epoxy-janthitrems in hay is yet to be determined. As such, both alkaloids may present a risk of toxicity when hay is fed to livestock.

\section{ACKNOWLEDGEMENTS}

Amy Watson for alkaloid analyses.

\section{REFERENCES}

Fink-Gremmels, J. 2005. Mycotoxins in forages. pp. 249-268. In: The Mycotoxin Blue Book. Eds. Diaz, D.E., Nottingham University Press, Nottingham.

Fletcher, L.R. 2005. Managing ryegrass-endophyte toxicoses. pp. 229-241. In: Neotyphodium in Cool-Season Grasses. Eds. Roberts, C.A.; West, C.P.; Spiers, D.E., Blackwell Publishing, Ames, IA.

Gallagher, R.T.; Hawkes, A.D.; Stewart, J.M. 1985. Rapid determination of the neurotoxin lolitrem $B$ in perennial ryegrass by high-performance liquid chromatography with fluorescence detection. Journal of Chromatography 321: 217-226.

Hume, D.E.; Popay, A.J.; Cooper, B.M.; Eerens, J.P.J.; Lyons, T.B.; Pennell, C.G.L.; Tapper, B.A.; Latch, G.C.M.; Baird, D.B. 2004. Effect of a novel endophyte on the productivity of perennial ryegrass (Lolium perenne) in New Zealand. Poster 313. In: Proceedings of the 5th International Symposium on Neotyphodium/ Grass Interactions. Eds. Kallenbach, R.; Rosenkranz, C. Jr.; Lock, T.R., Fayetteville, Arkansas.

Smetham, M.L. 1990. The conservation of herbage as hay or silage. pp. 337-369. In: Pastures their Ecology and Management. Ed. Langer, R.H.M., Oxford University Press, Auckland.

Spiering, M.J.; Davies, E.; Tapper, B.A.; Schmid, J.; Lane, G.A. 2002. Simplified extraction of ergovaline and peramine for analysis of tissue distribution in endophyte-infected grass tillers. Journal of Agricultural and Food Chemistry 50: 5856-5862.

Tapper, B.A.; Lane, G.A. 2004. Janthitrems found in a Neotyphodium endophyte of perennial ryegrass. Poster 301. In: Proceedings of the 5th International Symposium on Neotyphodium/ Grass Interactions. Eds. Kallenbach, R.; Rosenkranz, C. Jr.; Lock, T.R., Fayetteville, Arkansas. 